\title{
Immunological Microenvironment Predicts the Survival of the Patients with Hepatocellular Carcinoma Treated with Anti-PD-1 Antibody
}

\author{
Masahiro Morita ${ }^{a}$ Naoshi Nishida ${ }^{a}$ Kazuko Sakai $^{\mathrm{b}}$ Tomoko Aoki $^{\mathrm{a}}$ \\ Hirokazu Chishina $^{a}$ Masahiro Takita ${ }^{a}$ Hiroshi lda ${ }^{a}$ Satoru Hagiwara ${ }^{a}$

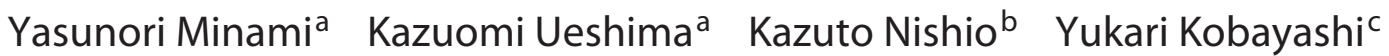 \\ Kazuhiro Kakimic Masatoshi Kudo ${ }^{a}$ \\ aDepartment of Gastroenterology and Hepatology, Kindai University Faculty of Medicine, Osaka, Japan; \\ ${ }^{b}$ Department of Genome Biology, Kindai University Faculty of Medicine, Osaka, Japan; 'Department of \\ Immunotherapeutics, The University of Tokyo Hospital, Tokyo, Japan
}

\section{Keywords}

Hepatocellular carcinoma - Wnt/ $\beta$-Catenin pathway · Immune checkpoint inhibitors · Survival · Immunological microenvironment

\begin{abstract}
Introduction: Although immune checkpoint inhibitors (ICls) have been considered as promising agents for the treatment of advanced hepatocellular carcinoma (HCC), previous clinical trials revealed that the response to anti-programmed cell death protein 1 (anti-PD-1) monotherapy was as low as $20 \%$. Identifying subgroups that respond well to $\mathrm{ICls}$ is clinically important. Here, we studied the prognostic factors for antiPD-1 antibody treatment based on the molecular and immunological features of HCC. Methods: Patients who were administered anti-PD1 antibody for advanced HCC at Kindai University Hospital were included. Clinicopathological backgrounds and antitumor responses were examined in 34 cases where tumor tissues before treatment were available. Transcriptome analysis was performed using 40 HCC samples obtained from surgical resection, and immune status was compared between $20 \mathrm{HCCs}$ with activating mutations
\end{abstract}

karger@karger.com www.karger.com/lic

Karger"

BOPEN ACCESS
(C) 2021 The Author(s)

Published by S. Karger AG, Basel

This is an Open Access article licensed under the Creative Commons Attribution-NonCommercial-4.0 International License (CC BY-NC) (http://www.karger.com/Services/OpenAccessLicense), applicable to the online version of the article only. Usage and distribution for commercial purposes requires written permission. in $\beta$-catenin and those without the mutations using transcriptome-based immunogram. Results: Univariate analysis showed that the disease control rate was significantly better in patients with a-fetoprotein $<400 \mathrm{ng} / \mathrm{mL}$, negative for $\beta$-catenin/glutamate synthetase (GS) staining, high combined positive score (CPS) of programmed death-ligand 1 (PD-L1), and increased infiltration of $\mathrm{CD}^{+}$cells in tumor tissues. Among them, negative staining of $\beta$-catenin/GS, CPS of $\mathrm{PD}-\mathrm{L} 1 \geq 1$, and high degree of $\mathrm{CD} 8^{+}$tumor-infiltrating lymphocytes (TILs) were significantly associated with longer survival in both progression-free survival (PFS) and overall survival (OS). The combination of these factors well stratified the survival of the patients on anti-PD- 1 antibody in both PFS and OS $(p<0.0001$ and $p=0.0048$ for PFS and OS, respectively). In addition, the immunogram revealed that tumorcarrying mutations in $\beta$-catenin showed downregulation of immune-related genes, especially in those related to priming and activation by dendritic cells, interferon- $\gamma$ response, inhibitory molecules, and regulatory $\mathrm{T}$ cells. Discussion/ Conclusion: The combined score including $\mathrm{Wnt} / \beta$-catenin activation, CPS of PD-L1, and degree of CD8 ${ }^{+}$TILs in HCC is informative for predicting the response to $\mathrm{ICl}$ in $\mathrm{HCC}$ cases. Constitutive activation of $\beta$-catenin can induce an immune
Correspondence to:

Naoshi Nishida,naoshi@med.kindai.ac.jp 
cold phenotype with downregulation of immune-related genes, and immunohistochemistry-based evaluation is beneficial for identifying the subgroup that shows a good response to $\mathrm{ICl}$.

(c) 2021 The Author(s).

Published by S. Karger AG, Basel

\section{Introduction}

Hepatocellular carcinoma (HCC) is one of the most common malignancies and a leading cause of cancer-related mortality worldwide $[1,2]$. Although there is recent progress in locoregional treatment of HCC, recurrence after curative treatment leads to tumor progression, where systemic chemotherapy is inevitable. Although several studies have reported the impact of molecular targeted agents (MTAs) on the survival of advanced HCC [3-7], the accumulation of genetic and epigenetic alterations in cancer cells may result in the resistance of HCC to MTAs, where escape from the inhibitory effect on tumor growth by MTAs will occur. From this point of view, intervention in the immune microenvironment should be a promising approach for patients with advancedstage HCC.

In recent years, several clinical trials of immune checkpoint inhibitors (ICIs) have been performed in patients with HCC. A phase-I/II clinical trial (CheckMate 040) using the anti-programmed cell death protein 1 (anti-PD-1) antibody nivolumab revealed an objective response rate (ORR) of $20 \%$ and disease control rate (DCR) of $64 \%$ in patients with advanced tumors in the 1st-line setting [8]. Another phase-II trial using the anti-PD-1 antibody pembrolizumab (KEYNOTE-224) showed an ORR of $17 \%$ and DCR of $62 \%$ in patients who showed tumor progression on sorafenib [9]. However, the phase-III clinical trial failed to show positive results on survival using pembrolizumab in advanced HCC cases, although higher antitumor responses were observed in the groups treated with the anti-PD-1 antibody compared to the control groups $[10,11]$. Collectively, almost $80 \%$ of the patients with HCC do not respond effectively to anti-PD-1 monotherapy, indicating that identification of a subgroup that would show a good response to ICIs is crucial for the management of HCC, especially in patients who fail to show antitumor response to MTAs.

On the other hand, recent reports suggest that Wnt/ $\beta$ catenin signaling may be involved in the exclusion of $\mathrm{CD}^{+}$cells in tumor tissues in melanoma cases [12]. Ruiz de Galarreta et al. [13] showed the role of $\beta$-catenin acti- vation in immune escape and resistance to anti-PD-1 therapy in a mouse model of HCC. Harding et al. [14] also showed a negative impact of $\mathrm{Wnt} / \beta$-catenin activation on DCR and progression-free survival (PFS) with anti-PD-1 therapy. Therefore, constitutive activation of the Wnt/ $\beta$ catenin signaling, which is generally observed in around $30 \%$ of HCC by mutations of the genes involved in the $\mathrm{Wnt} / \beta$-catenin pathway [15], would be a promising marker for predicting immune resistance to anti-PD-1 therapy in HCC cases. However, clinical evidence for the role of Wnt/ $\beta$-catenin activation and subsequent acquisition of the "immune cold phenotype" that may affect the response to ICIs is still lacking in HCC cases. In this study, we focused on this clinical question and analyzed the status of $\mathrm{Wnt} / \beta$-catenin activation, and factors associated with antitumor immunity on ICIs, such as expression of immune checkpoint molecules and infiltration of $\mathrm{CD} 8^{+}$ cells, in HCC tissues of patients who underwent antiPD-1 monotherapy thereafter. In addition, to determine the role of the activating mutation of $\mathrm{Wnt} / \beta$-catenin signaling on immune phenotype, characteristics of the immunological microenvironment of HCCs were examined using the transcriptome data of HCC tissues in the context of activating mutations in the $\mathrm{Wnt} / \beta$-catenin pathway.

\section{Materials and Methods}

\section{Patients and Follow-Up Schedule}

Between August 2015 and September 2017, 45 patients with advanced stage of HCC were treated with anti-PD-1 antibody monotherapy under clinical trials and real-world clinical practice at Kindai University Hospital. Among them, HCC tissues before treatment were available for 35 patients; 34 were eligible for immunohistochemical evaluations. Details of the administration and follow-up schedule are shown in the see online suppl. Material and methods; see www.karger.com/doi/10.1159/000516899 for all online suppl. material. We analyzed the background of these $34 \mathrm{pa}-$ tients who received anti-PD-1 monotherapy and examined the prognosis, including DCR, ORR, PFS, and overall survival (OS).

We also collected data associated with tumor progression and systemic inflammation from blood examination, including a-fetoprotein (AFP), lymphocyte count, red blood cell distribution width (RDW), neutrophil-to-lymphocyte ratio (NLR), plateletlymphocyte ratio (PLR), and lactate dehydrogenase (LDH) because these laboratory findings were reportedly associated with the tumor response to ICIs in other types of cancer [16-20]. Based on the previous reports, cut-off values of each blood chemical data for analyzing the efficacy of ICIs in tumor response were set as follows: baseline AFP $\geq 400 \mathrm{ng} / \mathrm{mL}$, lymphocyte count $\geq 1,000 / \mu \mathrm{L}$, RDW $\geq 16 \%$, NLR $\geq 5, P L R \geq 200$, and LDH $\geq$ upper normal limit, respectively [17-20]. 
Evaluation of Effectiveness

Antitumor responses were evaluated by the attending physicians according to RECIST version 1.1 [21]. Complete response (CR), partial response (PR), or stable disease (SD) persisting for $\geq 4$ months were considered as disease control (DC) based on the report regarding treatment using ICIs in patients with HCC [14]. Objective response was defined as PR or CR.

\section{Immunohistochemistry}

We reviewed formalin-fixed paraffin embedded (FFPE) tumor samples obtained from the HCC tissues before the treatment and confirmed the histology of HCC by at least 2 liver specialized pathologists. To determine the activation of the Wnt/ $\beta$-catenin pathway, we examined the expression of $\beta$-catenin and its downstream target, glutamine synthetase (GS), using immunohistochemistry (IHC). It is reported that nuclear staining of $\beta$-catenin is associated with the activating mutation of the catenin beta-1 (CTNNB1) gene [22-24]. Furthermore, strong diffuse expression of GS reportedly reflects constitutive activation of $\mathrm{Wnt} / \beta$-catenin signaling, that is attributed to the $\beta$-catenin mutation [25]. Therefore, the presence of nuclear staining of $\beta$-catenin in $\geq 5 \%$ of tumor cells $[26,27]$, or diffuse strong staining of GS were considered as positive findings for activation in Wnt/ $\beta$-catenin signaling [27-29].

On the other hand, it is conceivable that infiltration of $\mathrm{CD}^{+}$ lymphocytes in cancerous tissues and expression of programmed death-ligand 1 (PD-L1) are also associated with the response of tumors to anti-PD-1 therapy because blockade of the PD-1/PD-L1 axis should restore the antitumor immunity induced by $\mathrm{CD} 8^{+}$lymphocytes in tumors $[30,31]$. For this purpose, we performed IHC for CD8 and PD-L1 using the same tissues examined for the expression of $\beta$-catenin and GS. We counted the number of PD-L1positive cells in tumor and tumor-infiltrated cells to calculate the combined positive score (CPS) as reported previously, where CPS was determined as the number of PD-L1-positive cells (tumor cells, lymphocytes, and macrophages) divided by the total number of viable tumor cells $\times 100$ [9]; CPS of PD-L1 (PD-L1-CPS) as reported previously [9]. The number of tumor-infiltrating lymphocytes (TILs) expressing CD8 was also counted. Cells expressing $\beta$-catenin, GS, PD-L1, and CD8 were visually counted and quantified at 400-fold magnification. Based on the CPS shown in the results of phase-II clinical trial of pembrolizumab, where PD-L1CPS was positively associated with antitumor response to ICIs, CPS $\geq 1$ was defined as high PD-L1-CPS and CPS $<1$ was defined as low PD-L1-CPS [9]. Regarding the expression of CD8, the mean degree of $\mathrm{CD}^{+}$TILs was 28.4 cells/HPF (95\% CI: $\left.16.3-40.5\right)$ in tumors; values above the mean $(28.4$ cells/HPF) were defined as high degree of $\mathrm{CD}^{+}$TILs $[30,32]$. Details of the conditions of the IHCs are shown in the online suppl. materials and methods.

Mutational and Transcriptome Analyses of HCC Tissues

Previously, we analyzed the mutational status of 154 HCC samples using the Ion AmpliSeq ${ }^{\mathrm{TM}}$ Comprehensive Cancer Panel that covered somatic mutations across 409 cancer-associated genes (Illumina ${ }^{\circledR}$, San Diego, CA, USA) [31]. To determine the effect of activation of the $\mathrm{Wnt} / \beta$-catenin pathway on the antitumor immune response of HCC tissues, we compared the gene expression that determined the immune status in tumors between those with the CTNNB1 mutation and those without mutations using 40 fresh-frozen HCC samples, where 20 were from HCC with activating CTNNB1 mutation and 20 were from those with wild-type
CTNNB1. For the extraction of RNA from FFPE samples, we used the AllPrep DNA/RNA FFPE kit (QIAGEN, Venlo, the Netherlands). For library preparation of transcriptome analysis using next-generation sequencing, the Ion AmpliSeq Transcriptome $\mathrm{Hu}$ man Gene Expression Kit (Thermo Fisher Scientific, Inc., Waltham, MA, USA) was used according to the manufacturer's protocol. Sequencing was performed using the Ion $550 \mathrm{Kit}$ and the Ion S5 ${ }^{\mathrm{TM}} \mathrm{XL}$ System (Thermo Fisher Scientific, Inc., Waltham, MA, USA).

For the comprehension of the immunological microenvironment of the tumor, we constructed the immunogram, a scoring system based on RNA-sequence data describing individual cancerimmunity interactions [33-35]. We performed single-sample gene set enrichment analysis (ssGSEA) of these 40 tumors with 10 gene sets, innate immunity: natural killer cells (axis 1), priming and activation: dendritic cells (DCs) (axis 2), T cells: $\mathrm{CD}^{+} \mathrm{T}$-cell response (axis 3), interferon- $\gamma$ (IFNG) response (axis 4), inhibitory molecules (axis 5), inhibitory cells (regulatory T cells, axis 6), inhibitory cells (myeloid-derived suppressor cells, axis 7), recognition of tumor cells, antigen processing and presentation (axis 8), proliferation (axis 9), and glycolysis (axis 10), as described previously [34]. We obtained the mean (M) and standard deviation (SD) of the ssGSEA scores of the 40 HCC patients for each gene set. The immunogram score (IGS) for each axis was calculated as IGS $=3+1.5 \times($ ssGSEA score $-\mathrm{M}) / \mathrm{SD}[34]$. This formula was applied to all the axes of the immunogram in each patient. To depict immunograms on radar chart, the lower and upper limits of the IGS were set at 1 and 5, respectively.

\section{Statistics}

We used Pearson's $\chi^{2}$ test or Fisher's exact test for the comparison of categorical variables and the Wilcoxon rank-sum test for continuous variables. Nominal logistic regression analysis was used for the multivariate analysis. For the survival analysis, the Kaplan-Meier survival curve was used, and the $p$ value was calculated using the log-rank test. The details of the immunogram, shown using radar charts, have been reported previously [34]; hierarchical clustering analysis was performed using IGS and for the characterization of the transcriptome-based immune status of HCC with the CTNNB1 mutation. All $p$ values were 2 -sided, and $p<0.05$ was considered statistically significant. All statistical analyses were conducted using the JMP v.14 software (SAS Institute Inc., Cary, NC, USA).

\section{Results}

\section{Backgrounds of the Patients}

Clinical backgrounds of the patients are as follows: the average age was 67.1 years, 28 patients were male, and 6 were female. Nine patients were positive for hepatitis $B$ surface antigen, and 13 were positive for hepatitis $\mathrm{C}$ antibody. Sixteen HCCs were well differentiated, and 18 were moderately to poorly differentiated tumors. Portal vein tumor thrombus and extrahepatic spread were observed in 10 and 14 patients, respectively. Fourteen patients had tumors with Barcelona Clinic Liver Cancer (BCLC) stage $\mathrm{B}$ and 20 patients with BCLC stage C. Regarding back- 
Table 1. Backgrounds of the patients in this study

\begin{tabular}{|c|c|}
\hline Clinocopathological backgrounds & Distribution \\
\hline Age: median, distribution, $\mathrm{y}$ & $67.1,40$ \\
\hline Sex (male/female) & $28 / 6$ \\
\hline ECOG performance status (PS0/PS1) & $33 / 1$ \\
\hline HBV (yes/no) & $9 / 25$ \\
\hline HCV (yes/no) & $13 / 21$ \\
\hline Differentiation (well/moder & 16 \\
\hline PVTT (yes/no) & $10 / 24$ \\
\hline EHS (yes/no) & $14 / 20$ \\
\hline BCLC stag & $14 / 20$ \\
\hline Pretreatment of sorafenib ( $\mathrm{y}$ & $13 / 21$ \\
\hline \multicolumn{2}{|l|}{ Serum AFP level: median, } \\
\hline Lymphocyte count: median, distribution, $/ \mu \mathrm{L}$ & $1,073.5,25$ \\
\hline RDW: median, distribution, $\%$ & $14.5,11.9-21.7$ \\
\hline NLR: median, distribution & $2.6,1.1-5.1$ \\
\hline lian, distribution & $123.6,51-287.1$ \\
\hline LDH: median, distribution, U/L & $265,180-582$ \\
\hline \multicolumn{2}{|c|}{$\begin{array}{l}\text { ECOG, Eastern Cooperative Oncology Group; HBV, hepatitis } \\
\text { B virus; HCV, hepatitis Cvirus; PVTT, portal vein tumor thrombus; } \\
\text { EHS, extrahepatic spread; BCLC stage, Barcelona Clinic Liver } \\
\text { Cancer stage; AFP, a-fetoprotein; RDW, red blood cell distribution } \\
\text { width; NLR, neutrophil-to-lymphocyte ratio; PLR, platelet- } \\
\text { lymphocyte ratio; LDH, lactate dehydrogenase. }\end{array}$} \\
\hline
\end{tabular}

ground liver function, all cases were Child-Pugh grade A. Among them, 13 had a history of pretreatment with sorafenib, and 21 had none (Table 1).

\section{IHC of $\beta$-catenin, Glutamine Synthetase, PD-L1, and} CD8 in HCC Tissues

We performed IHC for the expression of $\beta$-catenin, GS, PD-L1, and CD8 in HCC tissues before anti-PD-1 therapy (Fig. 1). Nine out of 34 (26.5\%) were positive for nuclear staining for $\beta$-catenin, 11 out of 34 were positive for diffuse strong staining of GS; collectively, activation of the Wnt/ $\beta$-catenin pathway was considered to be positive in 14 of the 34 cases (41.2\%). Similarly, cases with high-degree $\mathrm{CD}^{+}$TILs were observed in 9 out of 34 (26.5\%); the number of patients with high PD-L1-CPS was 13 of $30(43.3 \%)$ of the cases (Table 2).

\section{Association between Clinicopathological Backgrounds} and Response to Anti-PD-1 Therapy in HCC

Regarding the best response of the 34 patients who received anti-PD-1 monotherapy, CR, PR, SD, and PD were observed in 3, 2, 10, and 19 patients, respectively. Univariate analysis revealed that AFP $\geq 400 \mathrm{ng} / \mathrm{mL}$ was nega- tively associated with DC ( $p=0.0186$ by Pearson's $\chi^{2}$ test; Table 2). In addition, based on the IHC analyses, we found that $\mathrm{Wnt} / \beta$-catenin activation was negatively, and high degree of $\mathrm{CD}^{+}$TILs and high PD-L1-CPS were positively associated with achievement of DC on anti-PD-1 antibody $(p=0.0034$, for $\mathrm{Wnt} / \beta$-catenin activation, $p=$ 0.0252 for CD $8^{+}$TILs and $p=0.0352$ for PD-L1-CPS, respectively; Table 2). Subsequently, we performed multivariate analysis using serum AFP level, activation status of Wnt $/ \beta$-catenin, degree of CD8 ${ }^{+}$TILs, and PD-L1-CPS as covariables. Although no items were independently associated with achievement of DC, the status of Wnt/ $\beta$ catenin activation showed a borderline association $(p=$ 0.0509 by nominal logistic regression analysis, Fig. 2 ) and could mostly affect the achievement of DC on anti-PD-1 antibody, where the negative for $\mathrm{Wnt} / \beta$-catenin activation showed an odds ratio (OR) of 6.93 (95\% CI: $0.83-$ $57.78)$, followed by that for high PD-L1-CPS (OR $=4.87$, 95\% CI: $0.70-33.94)$, AFP $<400 \mathrm{ng} / \mathrm{mL}(\mathrm{OR}=3.86,95 \%$ CI; 0.57-26.07), and high-degree CD8 ${ }^{+}$TILs (OR $=2.17$, $95 \%$ CI; 0.26-18.35, Fig. 2). It is also reasonable to speculate that most benefit of immune therapy is derived from the patients with objective responses. Therefore, we analyzed association between objective response and clinicopathological findings although the number of the cases with objective response is small $(n=5)$. Univariate analysis revealed that $\mathrm{RDW} \geq 16 \%$ showed a borderline association with objective response ( $p=0.0476$ by Fisher's exact test, online suppl. Table 1).

As absence of $\mathrm{Wnt} / \beta$-catenin activation was associated with DC in univariate analysis and showed borderline association in multivariate analysis, we compared the background of the patients carrying HCCs with $\mathrm{Wnt} / \beta$-catenin activation and those without activation with respect to relevant clinical and prognostic parameters. Univariate analysis revealed that RDW $\geq 16 \%$ was negatively associated with $\mathrm{Wnt} / \beta$-catenin activation and low grade of CD8+ TILs showed borderline association $(p=0.0262$, and $p=0.0504$ for RDW $\geq 16 \%$ and grade of CD $8+$ TILs, respectively, by Fisher's exact test, online suppl. Table 2).

Survival of the Patients Stratified by the Expression of Wnt/B-Catenin Activation, PD-L1 Expression, $C D 8^{+}$

Cell Infiltration on PD-1/PD-L1 Blockade

Next, we examined the survival of the patients classified based on IHC findings as shown in Figure 3 depicting the survival curve of HCC patients after the initiation of anti-PD-1 monotherapy. No deaths occurred before PD judgment. The median PFS and 95\% CI were as follows: median PFS durations were 56.5 days (95\% CI: 42-89) and 

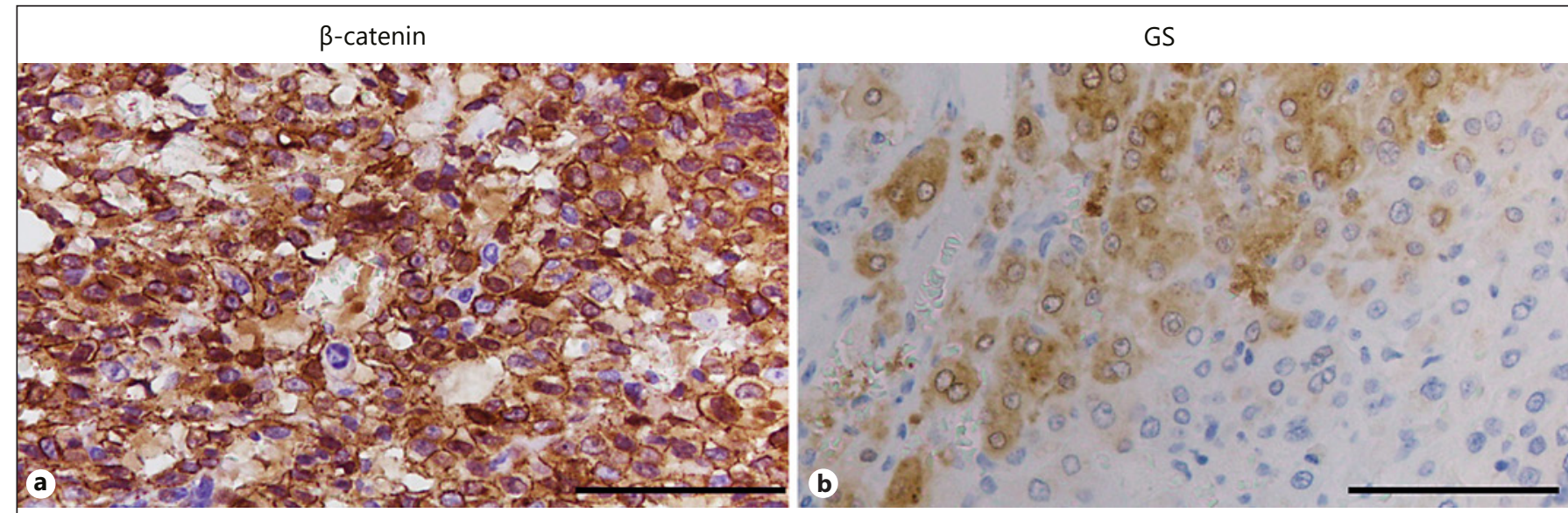

PD-L1

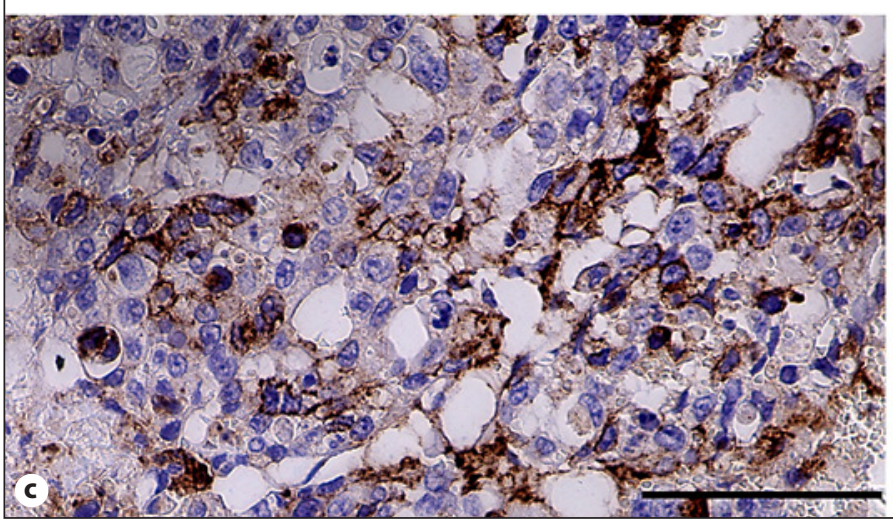

Fig. 1. Representative images of each immunostaining. Representative images of nuclear staining of $\beta$-catenin (a), strong diffuse expression of GS (b), expression of PD-L1 on cell membranes (c),

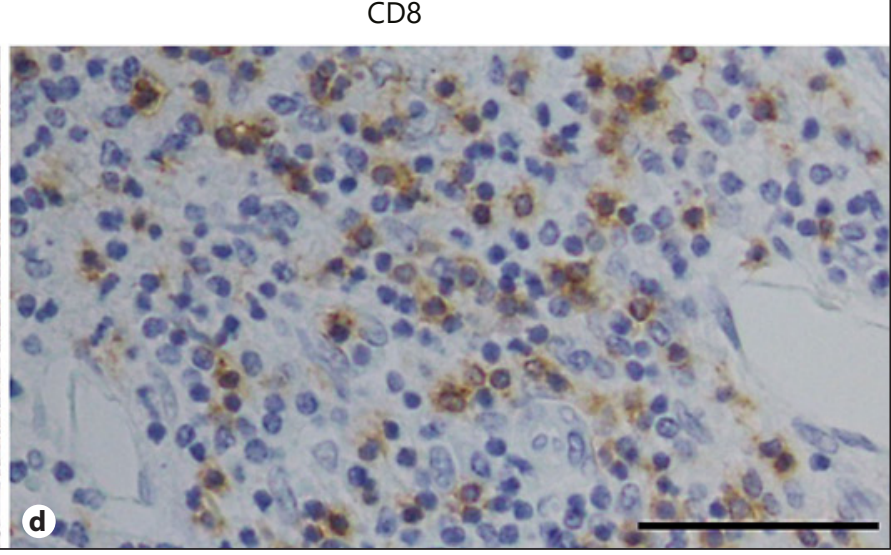

and infiltration of $\mathrm{CD}^{+}$lymphocytes in cancerous tissues (d) by IHC. Scale bar, $50 \mu \mathrm{m}$. GS, glutamate synthetase; IHC, immunohistochemistry.

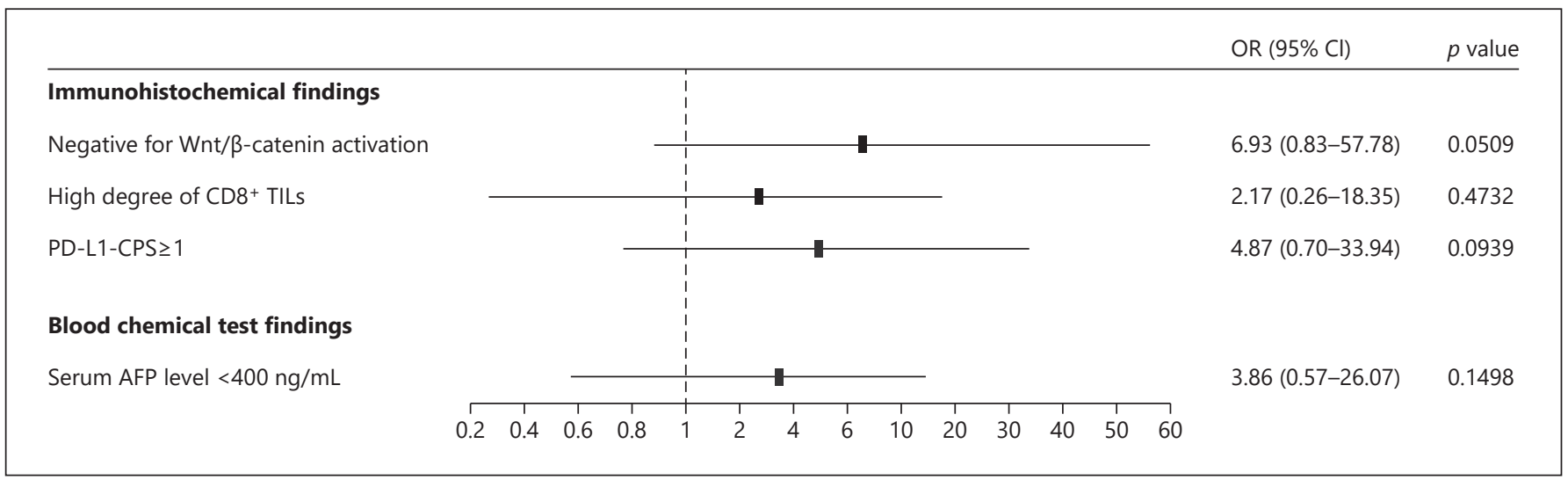

Fig. 2. Multivariate analysis and ORs for achievement of DC for $\mathrm{Wnt} / \beta$-catenin activation, PD-L1-CPS, CD8 ${ }^{+}$TILs, and serum AFP level. Multivariate analysis in DC was performed for Wnt $\beta$ catenin activation, combined with degree of $\mathrm{CD}^{+}$TILs, positive score of PD-L1 (PD-L1-CPS), and serum AFP level. Although no statistically significant difference was observed, the absence of $\mathrm{Wnt} / \beta$-catenin activation showed the highest $\mathrm{OR}=6.93$. $\mathrm{DC}$, disease control; CPS, combined positive score; TIL, tumor-infiltrating lymphocyte; OR, odds ratio; AFP, $\alpha$-fetoprotein; DC, disease control. 
Table 2. Association between clinicopathological findings and achievement of DC on the treatment with anti-PD-1 antibody in HCC patients

\begin{tabular}{|c|c|c|c|c|}
\hline Clinocopathological categories & \multicolumn{2}{|l|}{$\mathrm{DC}$} & $\begin{array}{l}p \text { value for } \\
\text { univariate } \\
\text { analysis }^{1}\end{array}$ & $\begin{array}{l}p \text { value for } \\
\text { multivariate } \\
\text { analysis }^{2}\end{array}$ \\
\hline \multicolumn{5}{|l|}{ Clinical backgrounds } \\
\hline Age $(<65 / \geq 65)$ & $5 / 10$ & $5 / 14$ & $0.7176^{*}$ & \\
\hline Sex (male/female) & $12 / 3$ & $16 / 3$ & $1.0000^{*}$ & \\
\hline ECOG performance status (PS0/PS1) & $15 / 0$ & $18 / 1$ & $1.0000^{*}$ & \\
\hline $\mathrm{HCV}$ (yes/no) & $6 / 9$ & $7 / 12$ & 0.8508 & \\
\hline Degree of differentiation (well/moderately - poorly) & $5 / 10$ & $11 / 8$ & 0.1542 & \\
\hline PVTT (yes/no) & $4 / 11$ & $6 / 13$ & $1.0000^{*}$ & \\
\hline EHS (yes/no) & $6 / 9$ & $8 / 11$ & 0.9014 & \\
\hline BCLC stage (B/C) & $6 / 9$ & $8 / 11$ & 0.9014 & \\
\hline Pretreatment of sorafenib (yes/no) & $8 / 7$ & $5 / 14$ & 0.1075 & \\
\hline NLR (high $[\geq 5] /$ low $(<5])$ & $1 / 14$ & $3 / 16$ & $0.6128^{*}$ & \\
\hline PLR (high $[\geq 200] /$ low $(<200])$ & $4 / 11$ & $3 / 16$ & $0.6722^{*}$ & \\
\hline LDH (high [ $\geq$ upper normal limit/low [<upper normal limit]) & $9 / 6$ & $11 / 8$ & 0.9014 & \\
\hline \multicolumn{5}{|l|}{ IHC } \\
\hline Wnt/ $\beta$-catenin activation (positive/negative) & $2 / 13$ & $12 / 7$ & 0.0034 & 0.0509 \\
\hline Grade of CD8+ TILs (high/low) & $7 / 8$ & $2 / 17$ & $0.0252^{*}$ & 0.4732 \\
\hline PD-L1-CPS (high $[\geq 1] /$ low $[<1]$ ) & $8 / 4$ & $5 / 13$ & 0.0352 & 0.0939 \\
\hline
\end{tabular}

Univariate analysis revealed that AFP $\geq 400 \mathrm{ng} / \mathrm{mL}$ was negatively associated with DC $(p=0.0186)$. In addition, based on the immunohistochemical analyses, Wnt/ $\beta$-catenin activation, which was determined by the nuclear staining of the $\beta$-catenin and/or strong diffuse staining of the glutamine synthetase, was negatively, and high CPS of PD-L1 (PD-L1-CPS) and high grade of CD8+ TILs were positively associated with achievement of DC on anti-PD- 1 antibody $(p=0.0034$, for Wnt $/ \beta$-catenin activation, $p=0.0352$ for PD-L1CPS, $p=0.0252$ for CD8+ TILs, respectively. Although, no items revealed independently associated with achievement of DC in multivariate analysis, status of Wnt $/ \beta$-catenin activation could mostly affect the achieving DC on anti-PD-1 antibody $(p=0.0509)$. ECOG, Eastern Cooperative Oncology Group; HBV, hepatitis B virus; HCV, hepatitis C virus; PVTT, portal vein tumor thrombus; EHS, extrahepatic spread; BCLC stage, Barcelona Clinic Liver Cancer stage; well, well differentiated; moderately poorly, moderately differentiated or poorly differentiated; AFP, a-fetoprotein; RDW, red blood cell distribution width; NLR, neutrophil-to-lymphocyte ratio; PLR, platelet-lymphocyte ratio; LDH, lactate dehydrogenase; TILs, tumor-infiltrating lymphocyte; PD-L1-CPS, combined positive score of programmed cell death-ligand 1; HCC, hepatocellular carcinoma; DC, disease control; IHC, immunochemistry. ${ }^{1} p$ value by Pearson's $\chi^{2}$ test or Fisher's exact test (The asterisk shows $p$ value by Fisher's exact test). Bolds denote the $p$ value $<0.05 .{ }^{2} p$ value by logistic regression analysis.

231 days (95\% CI: $115-547)$ in patients with positive for activation of the $\mathrm{Wnt} / \beta$-catenin pathway and those with negative for activation, respectively $(p<0.0001$ by logrank test, Fig. 3a). Similarly, the median PFS was 297 days (95\% CI: $89-514)$ and 58 days (95\% CI: $54-115)$ in patients with PD-L1-CPS $\geq 1$ and those with PD-L1-CPS $<1$ ( $p=0.0109$, Fig. $3 \mathrm{~b}$ ); median PFS durations were 246 days (95\% CI: $84-1,064)$ and 89 days (95\% CI: 56-164) in patients with a high degree of $\mathrm{CD} 8^{+}$TILs and those with a low degree of CD $8^{+}$TILs, respectively $(p=0.0344$, Fig. $3 c)$.
There was no significant difference in PFS among patients classified by serum AFP level. The median duration of PFS was 84 days (95\% CI: 56-164) and 210 days (95\% CI: $55-460)$ ( $p=0.2677$ by log-rank test, online suppl. Fig. 1a) in patients with $\mathrm{AFP} \geq 400 \mathrm{ng} / \mathrm{mL}$ and those with AFP $<400 \mathrm{ng} / \mathrm{mL}$.

The median OS and 95\% CI of each subgroup were as follows: median OS was 432 days (95\% CI: 103-487) and 764 days $(95 \%$ CI: $315-1,021)$ in patients with positive for activation of the Wnt/ $\beta$-catenin pathway and those with 
negative for activation, respectively ( $p=0.0003$ by logrank test, Fig. 4a). Similarly, the median durations of OS and their 95\% CI were 793 days (95\% CI: $315-1,163)$ and 432 days (95\% CI: $170-493)$ in patients with PD-L1-CPS $\geq 1$ and those with PD-L1-CPS $<1$, respectively $(p=0.0204$, Fig. 4b); median OS was 1,021 days (95\% CI: 170-not determined) and 487 days (95\% CI: 238-532) in patients with a high degree of $\mathrm{CD}^{+}$TILs and those with a low degree of CD $8^{+}$TILs ( $p=0.0089$, Fig. $4 c$ ), respectively. The median duration of OS was 430 days (95\% CI: 187-532) and 668.5 days $(95 \%$ CI: 466-1,163) in patients with AFP $\geq 400 \mathrm{ng} / \mathrm{mL}$ and those with AFP $<400 \mathrm{ng} / \mathrm{mL}$ ( $p=0.0289$ by log-rank test, online suppl. Fig. 1b).

Combined Immunohistochemical Findings for Wnt/ $\beta$-Catenin Activation, Expression of PD-L1, and Infiltration of $C D 8^{+}$Cells Stratified by the Prognosis of Patients with HCC on anti-PD-1 Antibody

In this analysis, we performed the assignment for Wnt/ $\beta$-catenin activation, PD-L1-CPS, and infiltration of CD8+ cells through IHC and found that the absence of staining for $\beta$-catenin or GS represented the most valuable risk for favorable prognosis of HCC patients on antiPD-1 therapy. However, high PD-L1-CPS and high degree of $\mathrm{CD}^{+}$TILs are also associated with a good tumor response to anti-PD-1 antibody. As IHC analyses sometimes yielded false-negative results because of the heterogeneity of staining in the tissue, and expression of PD-L1 and infiltration of $\mathrm{CD}^{+}$cells are also considered to be important for antitumor response to anti-PD-1 therapy, we assigned high PD-L1-CPS and high-degree $\mathrm{CD} 8^{+}$

Fig. 3. Kaplan-Meier curves of PFS on anti-PD-1 antibody in patients with HCC. PFS after the initiation of anti-PD-1 antibody administration was compared between HCC patients with positive and negative for activation of the $\mathrm{Wnt} / \beta$-catenin pathway (a), PDL1-CPS $\geq 1$ and PD-L1-CPS $<1$ (b), and a high degree of CD8+ TILs and a low degree of CD8+ TILs (c). The median PFS and 95\% CI were as follows: median durations of PFS were 56.5 days (95\% CI: $42-89)$ and 231 days (95\% CI: $115-547)$ in patients with positive for activation of the $\mathrm{Wnt} / \beta$-catenin pathway ( $\beta$-catenin activation +$)$ and those with negative for activation $(\beta$-catenin activation $-)$, respectively ( $p<0.0001$ by log-rank test; panel a). Similarly, the median PFS was 297 days (95\% CI: 89-514) and 58 days (95\% CI: $54-115$ ) in patients with a CPS of PD-L1 (PD-L1-CPS) $\geq 1$ and those with PD-L1-CPS $<1$ ( $p=0.0109$; panel b); median PFS durations were 246 days (95\% CI: 84-1,064) and 89 days (95\% CI: 56$164)$ in patients with a high degree of tumor-infiltrating $\mathrm{CD} 8^{+}$cells $\left(\mathrm{CD} 8^{+}\right.$high $)$and those with a low degree of tumor-infiltrated $\mathrm{CD}^{+}$cells $\left(\mathrm{CD}^{+}\right.$low $)$, respectively $(p=0.0344$; panel c). HCC, hepatocellular carcinoma; CPS, combined positive score; PFS, progression-free survival; TIL, tumor-infiltrating lymphocyte.
TILs, in addition to the negative staining of $\beta$-catenin or GS, as positive prognostic factors on ICIs, and studied the impact of accumulation of these 3 items on the prognosis of patients who received anti-PD-1 antibody. As shown in Figure 5, the median duration of PFS and 95\% CI for patients without any positive prognostic factors, those with 1 positive prognostic factor, and those with 2 or more factors were 55 days ( $95 \%$ CI: $37-100$ ), 89 days ( $95 \%$ CI; 42-460), and 271.5 days (95\% CI; 136-547), respec-

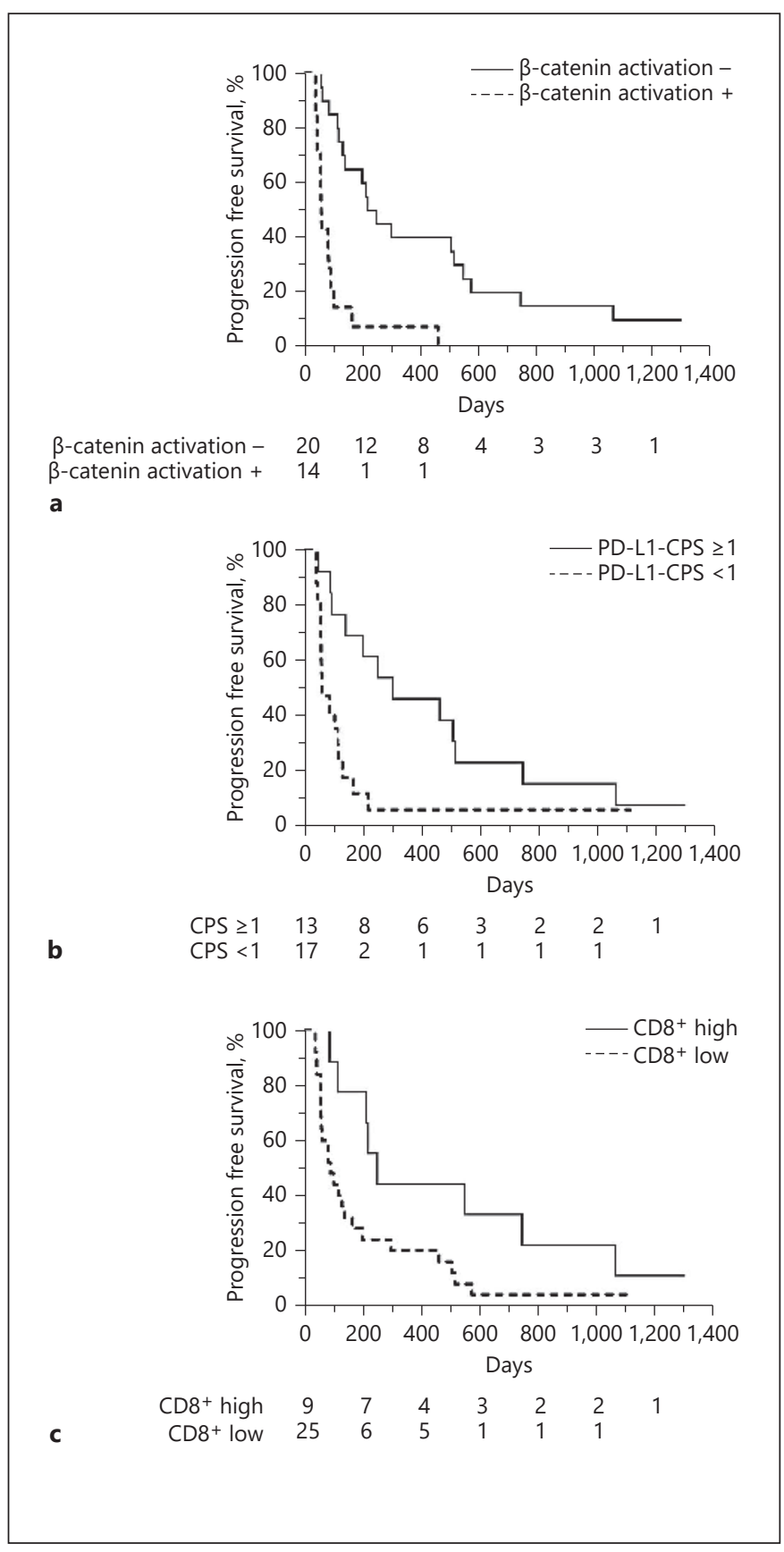


tively ( $p<0.0001$ by log-rank test, Fig. 5a). Similarly, the median duration of OS and 95\% CI for patients without any positive prognostic factors, those with 1 positive prognostic factor, and those with 2 or more factors were 432 days (95\% CI: 73-493), 479.5 days (95\% CI; $187-547)$, and 859 days (95\% CI; 225-1,163), respectively $(p=$ 0.0048 , Fig. 5b). This evidence suggests that comprehensive assessment of $\mathrm{Wnt} / \beta$-catenin activation and immune-related molecules could represent the immunological status that affects the response to anti-PD-1 therapy;

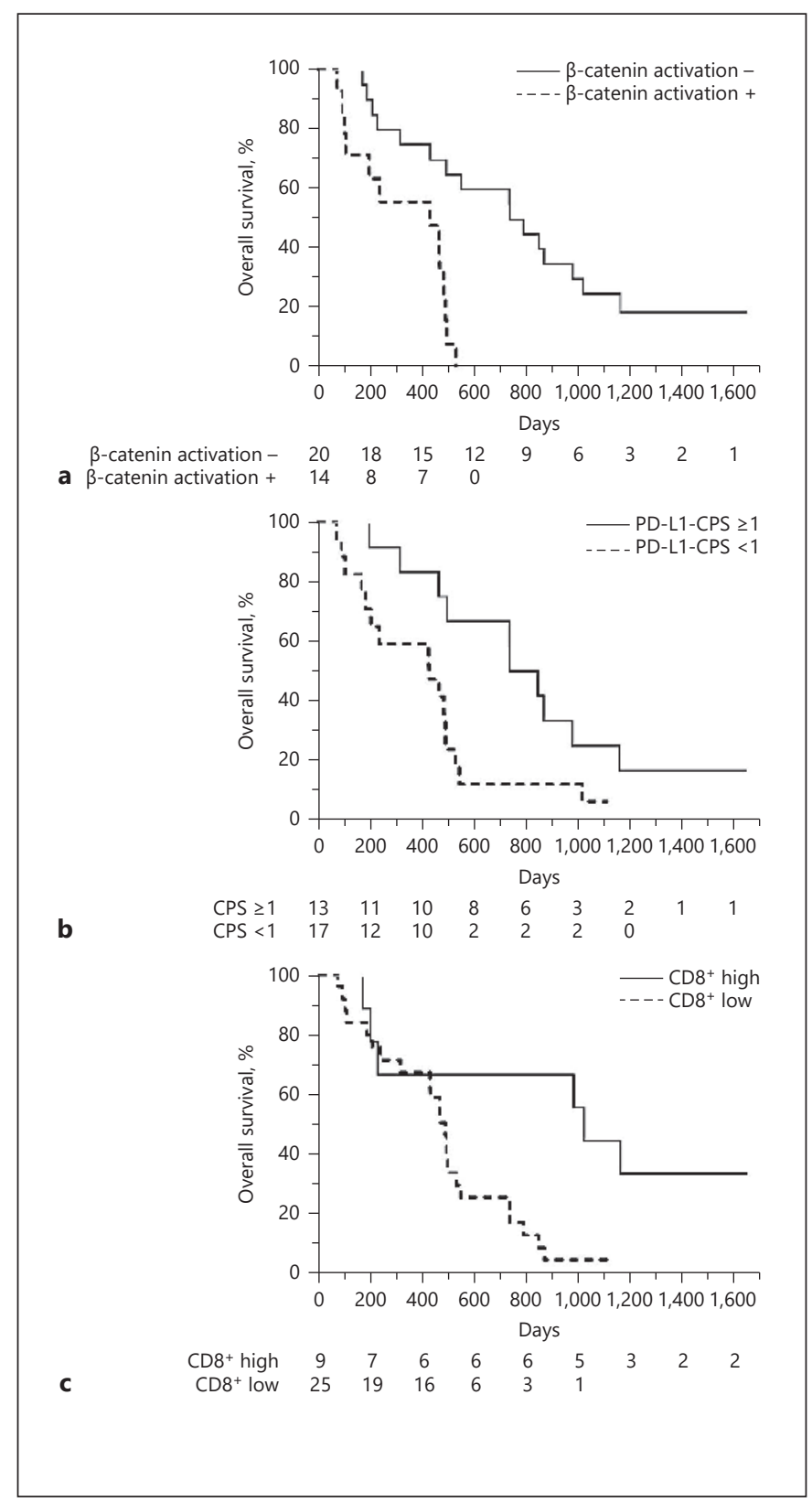

Prognostic Factors for PD-1/PD-L1 Blockade in HCC assessment of IHC could be a useful tool for selecting patients who may respond well to ICIs.

\section{Evaluation of the Immunological Microenvironment}

Using Transcriptome-Based Immunogram in HCC

with and without Activating Mutations in the Wnt/ $\beta$ -

Catenin Pathway

Constitutive activation of the $\mathrm{Wnt} / \beta$-catenin pathway in $\mathrm{HCC}$ is mostly due to mutations in the CTNNB1 gene $[15,36,37]$. The immunograms represent the 10 kinds of immune status classified using the ssGSEA and were shown in radar chart (online suppl. Fig. 2a). Each immunogram for $20 \mathrm{HCCs}$ with mutation in the CTNNB1 gene and $20 \mathrm{HCCs}$ without mutation in the CTNNB1 gene was shown in online suppl. Fig. 2b, c, respectively. We compared the IGS of each axis of the immunogram between 20 HCCs with mutations in CTNNB1 and 20 HCCs without mutations in CTNNB1 (Table 3). Among the 10 axes that represent the corresponding molecular profiles shown in the immunogram, no significant differences were found in axis 1 (innate immunity, $p=0.0884$ by Wilcoxon rank-sum test), axis 3 ( $\mathrm{T}$ cells, $p=0.0699$ ), axis 7 (inhibitory cells [myeloid-derived suppressor cells], $p=$ 0.0583 ), axis 8 (recognition of tumor cells, $p=0.1517$ ), axis 9 (proliferation, $p=0.0989$ ), and axis 10 (glycolysis, $p=0.3040)$. However, we found significant differences in axis 2 (priming and activation, $p=0.0020$ ), axis 4 (IFNG response, $p=0.0011$ ), axis 5 (inhibitory molecules, $p=$ 0.0265 ), and axis 6 (inhibitory cells [regulatory T cells], $p=0.0029$ ) (Table 3). Subsequently, we performed mul-

Fig. 4. Kaplan-Meier curves of OS on anti-PD-1 antibody in patients with HCC. The OS after the initiation of anti-PD-1 antibody was compared between HCC patients with positive and negative for activation of the Wnt/ $\beta$-catenin pathway (a), PD-L1-CPS $\geq 1$ and PD-L1-CPS $<1$ (b), and a high degree of CD8 ${ }^{+}$TILs and a low degree of CD8 ${ }^{+}$TILs (c). The median OS and their $95 \%$ CI of each subgroup were as follows: median OS, 432 days (95\% CI: 103-487), and 764 days $(95 \%$ CI: $315-1,021)$ in patients with positive for the $\mathrm{Wnt} / \beta$-catenin pathway $(\beta$-catenin activation +$)$ and those with negative for activation of this pathway ( $\beta$-catenin activation -), respectively ( $p=0.0003$ by log-rank test; panel a). The median durations of OS and their 95\% CI were 793 days (95\% CI: 315-1,163) and 432 days (95\% CI: 170-493) in patients with a CPS of PD-L1 (PD-L1-CPS) $\geq 1$ and those with PD-L1-CPS $<1$, respectively $(p=$ 0.0204; panel b); median OS was 1,021 days (95\% CI: 170 - not determined) and 487 days (95\% CI: 238-532) in patients with a high degree of tumor-infiltrated $\mathrm{CD} 8^{+}$cells $\left(\mathrm{CD} 8^{+}\right.$high) and those with a low degree of tumor-infiltrated $\mathrm{CD} 8^{+}$cells $\left(\mathrm{CD} 8^{+}\right.$low $)(p=$ 0.0089 ; panel c), respectively. HCC, hepatocellular carcinoma; CPS, combined positive score; OS, overall survival; CI, confidence interval; TIL, tumor-infiltrating lymphocyte. 
tivariate analysis using the IGS of each axis that showed a difference in univariate analysis for the mutational status of the CTNNB1 gene and found significant differences in axis 4 (IFNG response, $p=0.0490$; Table 3 ).

We performed hierarchical clustering analysis using IGS of each axis corresponding to the stage of the immune response, and successfully detected 2 clusters (clus-

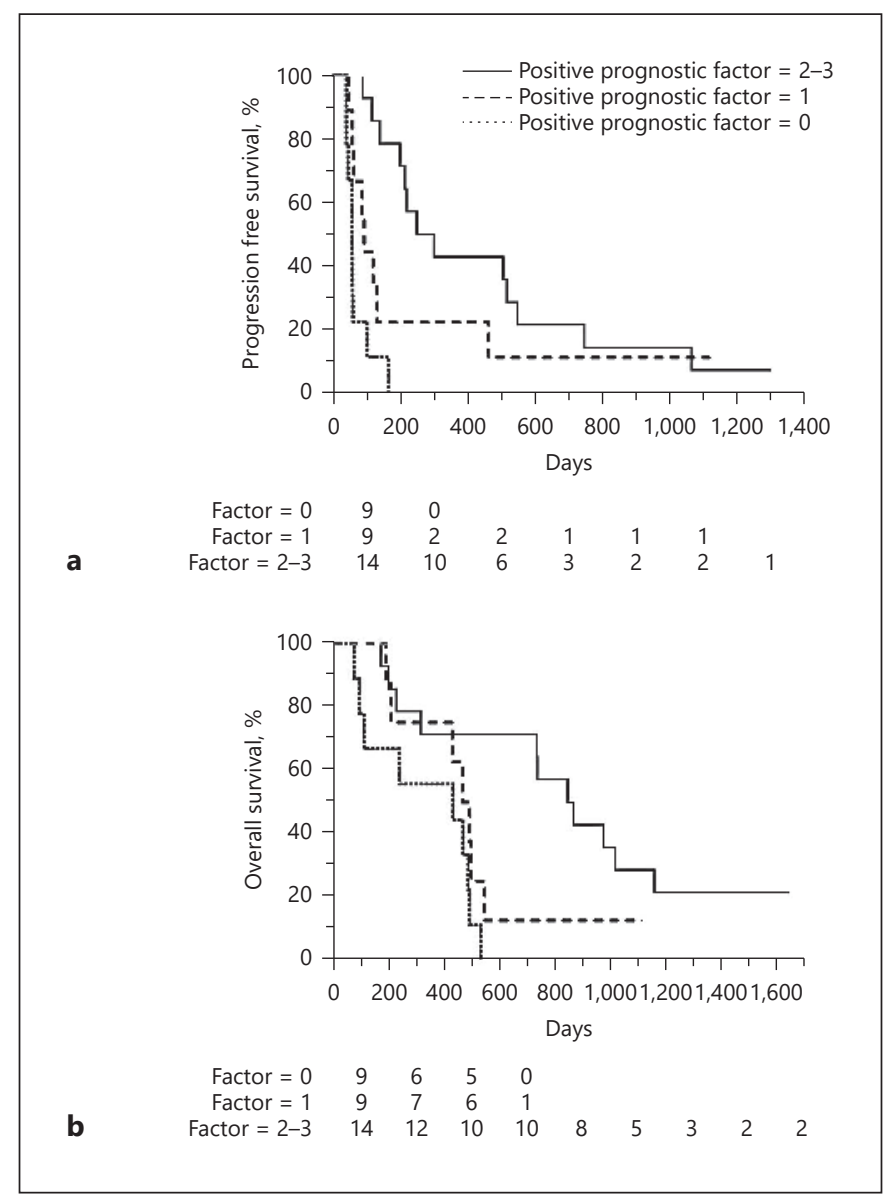

Fig. 5. Kaplan-Meier curves for survival classified based on the number of positive prognostic factors in patients with HCC. Kaplan-Meier curves for PFS and OS stratified by the members of positive prognostic factors are shown in $(\mathbf{a}, \mathbf{b})$, respectively. a The median duration of PFS and 95\% CI for patients without any positive prognostic factors (positive prognostic factor $=0$ ), those with one positive prognostic factor (positive prognostic factors $=1$ ), and those with 2 or more factors (positive prognostic factors $=2-3$ ) were 55 days (95\% CI; 37-100), 89 days (95\% CI; $42-460)$, and 271.5 days ( $95 \%$ CI; $136-547)$, respectively $(p<0.0001$ by log-rank test). b The median duration of OS and $95 \%$ CI for patients without any positive prognostic factors, those with one positive prognostic factor, and those with 2 or more factors were 432 days ( $95 \%$ CI; 73-493), 479.5 days (95\% CI; 187-547), and 859 days (95\% CI; $225-1,163)$, respectively ( $p=0.0048)$. HCC, hepatocellular carcinoma; PFS, progression-free survival; OS, overall survival. ter 1 and cluster 2 ) on a heatmap (online suppl. Fig. 3a); HCCs with CTNNB1 mutation tended to be predominant in cluster 1 that showed lower expression of immune-related genes, which should be attributed to the lower infiltration of immune cells ( $p=0.0578$ by Pearson's $\chi^{2}$ test, online suppl. Fig. 3b).

\section{Discussion/Conclusion}

Recent developments in systemic chemotherapy for HCC have improved the prognosis of patients with advanced HCC. For example, phase-III clinical trials for several MTAs, such as lenvatinib, sorafenib, regorafenib, ramucirumab, and cabozantinib have revealed the considerable effect of MTAs on survival [3-7]. However, acquired mutations in cancer cells induce resistance to TKIs because of the development of the escape pathway. On the other hand, ICIs are promising agents for the treatment of HCC, even in patients who show resistance to TKIs. It modulates the immune suppressive microenvironment, where mutations that induce resistance to ICI may rarely occur [38]. However, although phase-I/II clinical trial (CheckMate 040) and another phase-II clinical trial (KEYNOTE-224) of ICIs for HCC showed promising effects on survival, the phase-III clinical trial failed to show a superior effect on survival in patients who were treated with anti-PD-1 antibody compared to the control groups [8-10]. Based on the reports of the trials, around $20 \%$ of the patients showed tumor response to ICI monotherapies, suggesting that ICIs could be beneficial in a subset of patients with HCC, and currently, no effective biomarker has been established for predicting the effect of ICIs. It has also been reported that PD-L1 expression in tumors is associated with tumor response to this type of agent [20], indicating that the status of the tumor microenvironment is important to draw a benefit on ICI treatments. From this point of view, understanding the immunological microenvironment in HCC is required to develop biomarkers for ICIs in HCC treatment. In this study, we clearly showed that simple IHC-based analyses for evaluating immunological status could stratify the survival of patients with HCC on ICIs.

We examined the association between the data from the blood chemical test and tumor response to anti-PD-1 antibody. In our study, a significant association was observed between lower serum AFP levels and DC. Another report also showed that patients with serum AFP levels $<400 \mathrm{ng} / \mathrm{mL}$ tended to show a longer survival than those with serum AFP level $\geq 400 \mathrm{ng} / \mathrm{mL}$ on anti-PD-1 therapy 
Table 3. Presence or absence of the CTNNB1 mutation and immune status defined by the immunogram

\begin{tabular}{|c|c|c|c|c|}
\hline Immune status by immunogram & $\begin{array}{l}\text { CTNNB1 } \\
\text { mutation }\end{array}$ & $\begin{array}{l}\text { IGS median } \\
\text { (distribution) }\end{array}$ & $\begin{array}{l}p \text { value for } \\
\text { univariate } \\
\text { analysis } 1\end{array}$ & $\begin{array}{l}p \text { value for } \\
\text { multivariate } \\
\text { analysis }^{2}\end{array}$ \\
\hline Innate immunity (axis 1 ) & $\begin{array}{l}\text { With } \\
\text { Without }\end{array}$ & $\begin{array}{l}2.0(1.2-5.9) \\
3.5(0.9-8.2)\end{array}$ & 0.0884 & \\
\hline Priming and activation (axis 2) & $\begin{array}{l}\text { With } \\
\text { Without }\end{array}$ & $\begin{array}{l}2.2(0.1-4.8) \\
3.8(1.4-7.0)\end{array}$ & $0.0020^{3}$ & 0.5271 \\
\hline T cells (axis 3 ) & $\begin{array}{l}\text { With } \\
\text { Without }\end{array}$ & $\begin{array}{l}2.4(1.0-5.7) \\
3.3(1.1-7.4)\end{array}$ & 0.0699 & \\
\hline Interferon- $\gamma$ response (axis 4 ) & $\begin{array}{l}\text { With } \\
\text { Without }\end{array}$ & $\begin{array}{l}1.9(0.7-4.4) \\
3.8(1.5-6.2)\end{array}$ & 0.0011 & 0.0490 \\
\hline Inhibitory molecules (axis 5) & $\begin{array}{l}\text { With } \\
\text { Without }\end{array}$ & $\begin{array}{l}2.2(-0.3-5.2) \\
3.7(0.6-5.7)\end{array}$ & 0.0265 & 0.1173 \\
\hline Inhibitory cells (Tregs) (axis 6) & $\begin{array}{l}\text { With } \\
\text { Without }\end{array}$ & $\begin{array}{l}2.2(1.1-4.3) \\
3.2(1.3-8.4)\end{array}$ & 0.0029 & 0.8489 \\
\hline Inhibitory cells (MDSCs) (axis 7) & $\begin{array}{l}\text { With } \\
\text { Without }\end{array}$ & $\begin{array}{l}2.3(0.1-5.1) \\
3.9(0.6-6.3)\end{array}$ & 0.0583 & \\
\hline Recognition of tumor cells (axis 8) & $\begin{array}{l}\text { With } \\
\text { Without }\end{array}$ & $\begin{array}{l}2.5(0.1-4.5) \\
3.2(1.3-6.3)\end{array}$ & 0.1517 & \\
\hline Proliferation (axis 9) & $\begin{array}{l}\text { With } \\
\text { Without }\end{array}$ & $\begin{array}{l}3.1(-1.9-4.5) \\
3.4(1.2-5.4)\end{array}$ & 0.0989 & \\
\hline Glycolysis (axis 10) & $\begin{array}{l}\text { With } \\
\text { Without }\end{array}$ & $\begin{array}{l}2.8(0.6-5.4) \\
3.0(0.1-6.7)\end{array}$ & 0.3040 & \\
\hline
\end{tabular}

HCC, hepatocellular carcinoma; IGS, immunogram score; MDSC, myeloid-derived suppressor cell; Tregs, regulatory T cells. The IGS was compared between HCCs with and without mutation of the CTNNB1 gene in each axis of the immunological diagram. Twenty HCCs with and without CTNNB1 mutation, respectively, were analyzed for immunogram. Among the 10 axes that represent the corresponding molecular profiles shown in the immunogram, significant differences were found in the IGS of axis 2, axis 4, axis 5, and axis 6 depending on presence or absence of the CTNNB1 gene mutation. Multivariate analysis showed a significant difference for IGS in axis $4(p=0.0490) .{ }^{1} p$ value by Wilcoxon rank-sum test. ${ }^{2} p$ value by logistic regression analysis. ${ }^{3}$ Bolds denote the $p$ value $<0.05$.

[20]. In addition, other markers for systemic inflammation, such as elevated NLR and PLR, are also reportedly associated with poor prognosis in HCC [20]. Although we failed to show an association between NLR and PLR and tumor response, relatively small number of the analyzed cases may be attributed to the negative findings for the association between NLR, PLR, and tumor response. In contrast, lymphocyte count, RDW, and LDH have also been reported to be associated with a good response to ICI in lung cancer and melanoma cases [16-19]. In this study, we did not find any associations between these laboratory data and DCR in HCC cases although cases with high RDW were more frequent in patients who showed objective response (online suppl. Table 1). A larger cohort is required to determine the role of markers related to systemic inflammation as a biomarker of ICIs in HCC cases.

On the other hand, we found significant association between negative staining related to $\mathrm{Wnt} / \beta$-catenin activation, high grade of $\mathrm{CD}^{+}$TILs, and high PD-L1-CPS and DC. However, as the benefits of ICI are presumed to be large in the case of objective response, we also analyzed the relationship between clinical parameters and an achievement of objective response; borderline association was observed only for high RDW. It is possible that the number of objective response cases in this cohort was small that might not be enough for statistical analyses. A previous reportalso evaluated theimpact of Wnt $/ \beta$-catenin 
activation on anti-PD-1 therapy using DCR because ICI can be expected to have a long-term effect even in SD cases [14]. Therefore, it is reasonable to focus on DCR for tumor response, which may well reflect the longer survival on ICIs; further study with larger cohort containing more cases with objective response is required.

Contrastingly, it has been suggested that immune hot status is critical for the successful treatment of cancer with ICI $[39,40]$. In this context, currently, several studies showed the immune subclass of HCC based on the expression of cytokine, chemokine, immune checkpoint molecules, and infiltration of immune cells in the tumor [27, 41-45]. In addition, constitutive activation of the $\mathrm{Wnt} / \beta$-catenin pathway has been reported to be associated with the immune cold phenotype of cancer, including HCC $[12,13]$. Harding et al. [14] reported that HCC patients with activating mutations of the $\mathrm{Wnt} / \beta$-catenin pathway in tumors showed shorter PFS than those without mutations on treatment with ICIs. Recently, atezolizumab plus bevacizumab combination therapy was revealed to show a superior effect on antitumor response rate compared to ICI monotherapy $[8-10,46]$. From this point of view, it is intriguing to know the efficacy of combination of ICI with MTA on HCCs carrying Wnt/ $\beta$ catenin activation.

We also found that the absence of staining of the molecules in $\mathrm{Wnt} / \beta$-catenin signaling, high infiltration of $\mathrm{CD}^{+}$cells, and high CPS of PD-L1 were all significant contributors to the antitumor response on anti-PD-1 antibody. In addition, these findings were also associated with good prognosis. In this context, we hypothesized accumulation of these favorable factors might show an impact on the survival of the patients. As expected, the accumulation of these factors defined by IHC well stratifies the survival of HCC patients on anti-PD-1 antibody, suggesting that the immunological microenvironment should affect the survival of patients with HCC and IHC for assessing the activation of $\mathrm{Wnt} / \beta$-catenin signaling, degree of CD $8^{+}$TILs, and expression of PD-L1 is a simple and effective way to select patients who benefit from antiPD-1 antibody.

Finally, among the ORs of Wnt/ $\beta$-catenin activation, the degree of CD8 ${ }^{+}$TIL and PD-L1-CPS on DCR that of $\mathrm{Wnt} / \beta$-catenin activation showed the highest value, suggesting the impact of role of $\mathrm{Wnt} / \beta$-catenin signaling on the effect of ICIs in HCC cases. To clarify the characteristics of HCC with activation of the Wnt/ $\beta$-catenin pathway, we compared the immune status of tumors between HCCs with activating mutations in the CTNNB1 gene and those without mutation using transcriptome-based immunogram, where 10 molecular profiles that represent the characteristics of each immune step can be visualized [34]. In the HCC with CTNNB1 mutation, in addition to the IGS related to the priming and activation, IGS of the IFNG response, inhibitory molecules, and inhibitory cells were significantly lower in HCCs carrying the CTNNB1 mutation than in those without mutations, where the IFNG response showed the most prominent difference. This evidence clearly supports the idea that activation of the $\mathrm{Wnt} / \beta$-catenin pathway is associated with an immune cold phenotype with fewer infiltrating immune cells in tumor. On the contrary, tumors without CTNNB1 mutation may carry enough TILs, a subset of such HCC may have TILs showing an exhausted phenotype because the IGS of the inhibitory molecules (axis 5) and inhibitory cells (axis 6) is high in HCC without CTNNB1 mutation compared to those with the mutation, as suggested previously $[31,45,47,48]$.

We found a considerable effect of anti-PD-1 antibody on HCC cases with a lack of $\beta$-catenin activation, suggesting that blockade of the PD-1/PD-L1 axis might, at least partially, overcome the presence of exhausted TILs with other immunosuppressive molecules. Although the classification of HCCs using the hierarchical clustering analysis based on the IGS showed borderline significance for the association between the transcriptome-based immune phenotype and CTNNB1 mutation ( $p=0.0578$, online suppl. Fig. 3b), 2 axes that could be affected by the characteristics of cancer cells (axis 9 that represented proliferation and axis 10 showing glycolysis) were also involved in the immunogram, which might make the association between the transcriptome-based immune classification and CTNNB1 mutation obscure. Indeed, classification with hierarchical clustering analysis using IGS from axis 1 to 8 represented a significant difference in this association (data not shown). In addition, the expression of IFNG, which induces the expression of PD-L1 [49], was enhanced in HCC without $\beta$-catenin mutation. This evidence clearly supports the idea that the Wnt/ $\beta$ catenin pathway plays an important role in determining the immunological microenvironment of HCC.

The limitation of this study includes the fact that only 34 cases were analyzed, and most of the tissue was obtained from liver biopsy specimens, where heterogeneity of staining in IHC was observed. It is possible that there was a false-negative result for immune staining of immune-related molecules because of its heterogeneity in expression. Indeed, although the immunogram suggests the relationship between the mutation of CTNNB1 and immune cold phenotype, the IHC fails to show the sig- 
nificant association between the activation of $\mathrm{Wnt} / \beta$ catenin pathway and low grade of $\mathrm{CD}^{+}$TILs and PD-L1CPS, although the HCCs with $\mathrm{Wnt} / \beta$-catenin activation tend to carry low $\mathrm{CD}^{+}$TILs and PD-L1 expressions (online suppl. Table 2). Therefore, we believe that counting the total number of IHC findings, $\beta$-catenin/GS, CD8, and PD-L1 expression could minimize the false-negative results in terms of the presence of an immune cold phenotype. Another limitation of this study is only the limited molecules have been analyzed for evaluating immunological microenvironments of HCC. For example, several oncogenic signals are known to affect antitumor immunity [50]. Regarding HCC cases, a functional link between mutation of ARID2 and chemokine production related to tumor-associated macrophage, which led to noninflamed tumor, was reported [51]. Inactivation of Hippo pathway in HCC is also known to induce immune suppressive status through the induction of tumor-associated macrophage due to the expression of $\mathrm{C}$ - $\mathrm{C}$ motif chemokine 2 by yes-associated protein in mouse model [52]. Even in HCCs with enough TILs, a recent report showed that tumor related to nonalcoholic steatohepatitis (NASH) might be less responsive to ICIs, probably owing to the NASH-related aberrant T-cell activation that resulted in the impaired immune surveillance [53]. Because of the complexity of the antitumor immunity, data based on multi-omics analysis might be more informative for developing innovative biomarker of ICIs. Nevertheless, predicting the prognosis of HCC patients on ICIs by simple IHC evaluations is clinically significant because, currently, there are no biomarkers, and analysis using IHC is cost-effective compared to omics-based analysis. This result is considered beneficial for selecting the appropriate agents for personalized medicine in HCC treatment.

\section{Statement of Ethics}

The research was conducted ethically in accordance with the World Medical Association Declaration of Helsinki. The study protocol conforms to the ethical guidelines of the 1975 Declaration of Helsinki. We used archived tissue samples for this study that were obtained with patient's written consent. This study was approved by the Ethics Committee of Kindai University Hospital (IRB approved number: \#31-145).

\section{Conflict of Interest Statement}

Masatoshi Kudo reports honoraria and consulting or advisory fees from Bayer AG, Roche, and Eisai Co. Ltd.; honoraria from Bayer AG, Bristol Myers Squibb, EA Pharma Co., Ltd., Eisai Co. Ltd., and Merck Sharp \& Dohme; and research funding from Bayer AG, Daiichi Sankyo Co., Ltd., Chugai Pharmaceutical Co., Ltd., Merck Sharp \& Dohme, Otsuka Pharmaceutical Co., Ltd., Sumitomo Dainippon Pharma Co., Ltd., Ono Pharmaceutical Co., and Taiho Pharmaceutical. M.K. is an Editor-in-Chief, and N.N. is an Editorial Board member of Liver Cancer.

\section{Funding Sources}

This work was supported in part by a Grant-in-Aid for Scientific Research from the Japan Society for the Promotion of Science (KAKENHI: 16K09382, N. Nishida, and 18K07922, M Kudo) and a grant from Smoking Research Foundation (N. Nishida).

\section{Author Contributions}

Study concept and design: N.N. Acquisition of data: M.M., N.N., K.S., T.A., H.C., T.M., M.T., S.H., Y.M., H.I., K.U., and M.K. Analysis and interpretation of the data: M.M., N.N., K.S., K.N., Y.K., and K.K. Drafting of the manuscript: M.M. and N.N. Revision of the manuscript for intellectual content: all authors. Statistical analysis: M.M. and N.N. Study supervision: N.N. and M.K.

\section{References}

1 Altekruse SF, Henley SJ, Cucinelli JE, McGlynn KA. Changing hepatocellular carcinoma incidence and liver cancer mortality rates in the United States. Am J Gastroenterol. 2014 Apr;109(4):542-53.

2 Torre LA, Bray F, Siegel RL, Ferlay J, LortetTieulent J, Jemal A. Global cancer statistics, 2012. CA Cancer J Clin. 2015 Mar;65(2):87108.

3 Llovet JM, Ricci S, Mazzaferro V, Hilgard P, Gane E, Blanc JF, et al. Sorafenib in advanced hepatocellular carcinoma. N Engl J Med. 2008 Jul 24;359(4):378-90.
4 Bruix J, Qin S, Merle P, Granito A, Huang YH, Bodoky G, et al. Regorafenib for patients with hepatocellular carcinoma who progressed on sorafenib treatment (RESORCE): a randomised, double-blind, placebo-controlled, phase 3 trial. Lancet. 2017 Jan 7;389(10064): 56-66.

5 Kudo M, Finn RS, Qin S, Han KH, Ikeda K, Piscaglia F, et al. Lenvatinib versus sorafenib in first-line treatment of patients with unresectable hepatocellular carcinoma: a randomised phase 3 non-inferiority trial. Lancet. 2018 Mar 24;391(10126):1163-73.
6 Zhu AX, Kang YK, Yen CJ, Finn RS, Galle PR, Llovet JM, et al. Ramucirumab after sorafenib in patients with advanced hepatocellular carcinoma and increased $\alpha$-fetoprotein concentrations (REACH-2): a randomised, doubleblind, placebo-controlled, phase 3 trial. Lancet Oncol. 2019 Feb;20(2):282-96.

7 Abou-Alfa GK, Meyer T, Cheng AL, ElKhoueiry AB, Rimassa L, Ryoo BY, et al. Cabozantinib in patients with advanced and progressing hepatocellular carcinoma. $\mathrm{N}$ Engl J Med. 2018 Jul 5;379(1):54-63. 
8 El-Khoueiry AB, Sangro B, Yau T, Crocenzi TS, Kudo M, Hsu C, et al. Nivolumab in patients with advanced hepatocellular carcinoma (CheckMate 040): an open-label, noncomparative, phase $1 / 2$ dose escalation and expansion trial. Lancet. 2017 Jun 24; 389(10088):2492-502.

9 Zhu AX, Finn RS, Edeline J, Cattan S, Ogasawara S, Palmer D, et al. Pembrolizumab in patients with advanced hepatocellular carcinoma previously treated with sorafenib (KEYNOTE-224): a non-randomised, openlabel phase 2 trial. Lancet Oncol. 2018 Jul; 19(7):940-52.

10 Finn RS, Ryoo BY, Merle P, Kudo M, Bouattour M, Lim HY, et al. Pembrolizumab as second-line therapy in patients with advanced hepatocellular carcinoma in keynote-240: a randomized, double-blind, phase III trial. J Clin Oncol. 2020 Jan 20;38(3):193-202.

11 Yau T, Park JW, Finn RS, Cheng A-L, Mathurin P, Edeline J, et al. CheckMate 459: a randomized, multi-center phase 3 study of nivolumab (NIVO) vs sorafenib (SOR) as first-line (1L) treatment in patients (pts) with advanced hepatocellular carcinoma (aHCC). Ann Oncol. 2019 Oct;30(Suppl 5):v874-v875.

12 Spranger S, Bao R, Gajewski TF. Melanomaintrinsic $\beta$-catenin signalling prevents antitumour immunity. Nature. 2015 Jul 9; 523(7559):231-5.

13 Ruiz de Galarreta M, Bresnahan E, MolinaSánchez P, Lindblad KE, Maier B, Sia D, et al. $\beta$-catenin activation promotes immune escape and resistance to anti-PD-1 therapy in hepatocellular carcinoma. Cancer Discov. 2019 Aug;9(8):1124-41.

14 Harding JJ, Nandakumar S, Armenia J, Khalil DN, Albano M, Ly M, et al. Prospective genotyping of hepatocellular carcinoma: clinical implications of next-generation sequencing for matching patients to targeted and immune therapies. Clin Cancer Res. 2019 Apr 1; 25(7):2116-26.

15 Llovet JM, Villanueva A, Lachenmayer A, Finn RS. Advances in targeted therapies for hepatocellular carcinoma in the genomic era. Nat Rev Clin Oncol. 2015 Jul;12(7):408-24.

16 Weide B, Martens A, Hassel JC, Berking C, Postow MA, Bisschop K, et al. Baseline biomarkers for outcome of melanoma patients treated with pembrolizumab. Clin Cancer Res. 2016 Nov 15;22(22):5487-96.

17 Tanizaki J, Haratani K, Hayashi H, Chiba Y, Nakamura Y, Yonesaka K, et al. Peripheral blood biomarkers associated with clinical outcome in non-small cell lung cancer patients treated with nivolumab. J Thorac Oncol. 2018 Jan;13(1):97-105.

18 Kiriu T, Yamamoto M, Nagano T, Koyama K, Katsurada M, Tamura D, et al. Prognostic value of red blood cell distribution width in nonsmall cell lung cancer treated with anti-programmed cell death-1 antibody. In Vivo. 2019 Jan-Feb;33(1):213-20.
19 Russo A, Russano M, Franchina T, Migliorino MR, Aprile G, Mansueto G, et al. Neutrophilto-lymphocyte ratio (NLR), platelet-to-lymphocyte ratio (PLR), and outcomes with nivolumab in pretreated non-small cell lung cancer (NSCLC): a large retrospective multicenter study. Adv Ther. 2020 Mar;37(3): 1145-55.

20 Sangro B, Melero I, Wadhawan S, Finn RS, Abou-Alfa GK, Cheng AL, et al. Association of inflammatory biomarkers with clinical outcomes in nivolumab-treated patients with advanced hepatocellular carcinoma. J Hepatol. 2020 Dec;73(6):1460-9.

21 Eisenhauer EA, Therasse P, Bogaerts J, Schwartz LH, Sargent D, Ford R, et al. New response evaluation criteria in solid tumours: revised RECIST guideline (version 1.1). Eur J Cancer. 2009 Jan;45(2):228-47.

22 Hsu HC, Jeng YM, Mao TL, Chu JS, Lai PL, Peng SY. Beta-catenin mutations are associated with a subset of low-stage hepatocellular carcinoma negative for hepatitis $B$ virus and with favorable prognosis. Am J Pathol. 2000 Sep;157(3):763-70.

23 Laurent-Puig P, Legoix P, Bluteau O, Belghiti J, Franco D, Binot F, et al. Genetic alterations associated with hepatocellular carcinomas define distinct pathways of hepatocarcinogenesis. Gastroenterology. 2001 Jun;120(7): 1763-73.

24 Chiang DY, Villanueva A, Hoshida Y, Peix J, Newell P, Minguez B, et al. Focal gains of VEGFA and molecular classification of hepatocellular carcinoma. Cancer Res. 2008 Aug 15;68(16):6779-88.

25 Zucman-Rossi J, Benhamouche S, Godard C, Boyault S, Grimber G, Balabaud C, et al. Differential effects of inactivated Axin 1 and activated beta-catenin mutations in human hepatocellular carcinomas. Oncogene. $2007 \mathrm{Feb}$; 26(5):774-80.

26 Durnez A, Verslype C, Nevens F, Fevery J, Aerts R, Pirenne J, et al. The clinicopathological and prognostic relevance of cytokeratin 7 and 19 expression in hepatocellular carcinoma. A possible progenitor cell origin. Histopathology. 2006 Aug;49(2):138-51.

27 Tsujikawa H, Masugi Y, Yamazaki K, Itano O, Kitagawa Y, Sakamoto M. Immunohistochemical molecular analysis indicates hepatocellular carcinoma subgroups that reflect tumor aggressiveness. Hum Pathol. 2016 Apr; 50:24-33.

28 Audard V, Grimber G, Elie C, Radenen B, Audebourg A, Letourneur F, et al. Cholestasis is a marker for hepatocellular carcinomas displaying beta-catenin mutations. J Pathol. 2007 Jul;212(3):345-52.

29 Ueno A, Masugi Y, Yamazaki K, Komuta M, Effendi K, Tanami $Y$, et al. OATP1B3 expression is strongly associated with $\mathrm{Wnt} / \beta$-catenin signalling and represents the transporter of gadoxetic acid in hepatocellular carcinoma. J Hepatol. 2014 Nov;61(5):1080-7.
30 Sideras K, Biermann K, Verheij J, Takkenberg BR, Mancham S, Hansen BE, et al. PD-L1, galectin-9 and CD8(+) tumor-infiltrating lymphocytes are associated with survival in hepatocellular carcinoma. Oncoimmunology. 2017;6(2):e1273309.

31 Nishida N, Sakai K, Morita M, Aoki T, Takita M, Hagiwara S, et al. Association between genetic and immunological background of hepatocellular carcinoma and expression of programmed cell death-1. Liver Cancer. 2020 Aug;9(4):426-39.

32 Brunner SM, Rubner C, Kesselring R, Martin $\mathrm{M}$, Griesshammer E, Ruemmele P, et al. Tumor-infiltrating, interleukin-33-producing effector-memory CD8(+) T cells in resected hepatocellular carcinoma prolong patient survival. Hepatology. 2015 Jun;61(6):195767.

33 Karasaki T, Nagayama K, Kuwano H, Nitadori II, Sato M, Anraku M, et al. An immunogram for the cancer-immunity cycle: towards personalized immunotherapy of lung cancer. J Thorac Oncol. 2017 May; 12(5):791-803.

34 Kobayashi Y, Kushihara Y, Saito N, Yamaguchi S, Kakimi K. A novel scoring method based on RNA-Seq immunograms describing individual cancer-immunity interactions. Cancer Sci. 2020 Aug 18;111(11):4031-40.

35 Sato Y, Wada I, Odaira K, Hosoi A, Kobayashi $Y$, Nagaoka $K$, et al. Integrative immunogenomic analysis of gastric cancer dictates novel immunological classification and the functional status of tumor-infiltrating cells. Clin Transl Immunology. 2020;9(10):e1194.

36 de La Coste A, Romagnolo B, Billuart P, Renard CA, Buendia MA, Soubrane O, et al. Somatic mutations of the beta-catenin gene are frequent in mouse and human hepatocellular carcinomas. Proc Natl Acad Sci USA. 1998 Jul 21;95(15):8847-51

37 Miyoshi Y, Iwao K, Nagasawa Y, Aihara T, Sasaki $Y$, Imaoka $S$, et al. Activation of the beta-catenin gene in primary hepatocellular carcinomas by somatic alterations involving exon 3. Cancer Res. 1998 Jun 15;58(12): 2524-7.

38 Nishida N, Kudo M. Immune checkpoint blockade for the treatment of human hepatocellular carcinoma. Hepatol Res. 2018 Jul; 48(8):622-34.

39 Gajewski TF, Schreiber H, Fu YX. Innate and adaptive immune cells in the tumor microenvironment. Nat Immunol. 2013 Oct;14(10): 1014-22.

40 Teng MW, Ngiow SF, Ribas A, Smyth MJ. Classifying cancers based on t-cell infiltration and PD-L1. Cancer Res. 2015 Jun 1;75(11): 2139-45.

41 Boyault S, Rickman DS, de Reyniès A, Balabaud C, Rebouissou S, Jeannot E, et al. Transcriptome classification of HCC is related to gene alterations and to new therapeutic targets. Hepatology. 2007 Jan;45(1):42-52. 
42 Hoshida Y, Nijman SM, Kobayashi M, Chan JA, Brunet JP, Chiang DY, et al. Integrative transcriptome analysis reveals common molecular subclasses of human hepatocellular carcinoma. Cancer Res. 2009 Sep 15;69(18): 7385-92.

43 Tan PS, Nakagawa S, Goossens N, Venkatesh A, Huang T, Ward SC, et al. Clinicopathological indices to predict hepatocellular carcinoma molecular classification. Liver Int. 2016 Jan;36(1):108-18.

44 Kurebayashi Y, Ojima H, Tsujikawa H, Kubota N, Maehara J, Abe Y, et al. Landscape of immune microenvironment in hepatocellular carcinoma and its additional impact on histological and molecular classification. Hepatology. 2018 Sep;68(3):1025-41.

45 Nishida N, Kudo M. Immune phenotype and immune checkpoint inhibitors for the treatment of human hepatocellular carcinoma. Cancers (Basel). 2020;12(5):1274.
46 Finn RS, Qin S, Ikeda M, Galle PR, Ducreux M, Kim TY, et al. Atezolizumab plus bevacizumab in unresectable hepatocellular carcinoma. N Engl J Med. 2020 May 14;382(20): 1894-905.

47 Sia D, Jiao Y, Martinez-Quetglas I, Kuchuk O, Villacorta-Martin C, Castro de Moura M, et al. Identification of an immune-specific class of hepatocellular carcinoma, based on molecular features. Gastroenterology. 2017 Sep; 153(3):812-26.

48 Kim HD, Song GW, Park S, Jung MK, Kim $\mathrm{MH}$, Kang HJ, et al. Association between expression level of PD1 by tumor-infiltrating CD8(+) T cells and features of hepatocellular carcinoma. Gastroenterology. 2018 Dec; 155(6):1936-50.e17.

49 Mimura K, Teh JL, Okayama H, Shiraishi K, Kua LF, Koh V, et al. PD-L1 expression is mainly regulated by interferon gamma associated with JAK-STAT pathway in gastric cancer. Cancer Sci. 2018 Jan;109(1):43-53.
50 Kobayashi Y, Lim SO, Yamaguchi H. Oncogenic signaling pathways associated with immune evasion and resistance to immune checkpoint inhibitors in cancer. Semin Cancer Biol. 2020 Oct;65:51-64.

51 Fujita M, Yamaguchi R, Hasegawa T, Shimada S, Arihiro K, Hayashi S, et al. Classification of primary liver cancer with immunosuppression mechanisms and correlation with genomic alterations. EBioMedicine. 2020 Mar; 53:102659.

52 Guo X, Zhao Y, Yan H, Yang Y, Shen S, Dai $\mathrm{X}$, et al. Single tumor-initiating cells evade immune clearance by recruiting type II macrophages. Genes Dev. 2017 Feb 1;31(3):247-59.

53 Pfister D, Núñez NG, Pinyol R, Govaere O, Pinter M, Szydlowska M, et al. NASH limits anti-tumour surveillance in immunotherapytreated HCC. Nature. 2021;592(7854):450-6. 